\title{
Anterior Cruciate Ligament Reconstruction by Combined Intra-Articular (K. Lambert) and Extra-Articular Iliotibial Band Tenodesis (Maclntosh; Autologous Grafts)
}

\author{
Samir Abdul-Razik Ibrahim \\ Orthopedic Unit, Al-Razi Orthopedic Hospital, Kuwait
}

\section{Key Words}

Anterior cruciate ligament · Autologous graft - Intra-articular reconstruction .

Extra-articular tenodesis - Continuous passive motion

\begin{abstract}
Objective: To assess the results of anterior cruciate ligament reconstruction in a group of sports players. Methods: A total of 153 sports players were reviewed 70 months (range 39-84 months) after they had anterior cruciate ligaments reconstruction by autologous patellar tendon graft (K. Lambert intraarticular reconstruction) combined with extra-articular tenodesis using iliotibial band (Maclntosh tenodesis). Results: We found all the patients were able to return to their normal active life and 131 atheletes were able to return to full sports activities, while 21 patients were not able to go back to their sports or had to modify their sports activities. The knees were assessed using Lysholm knee
\end{abstract}

\begin{tabular}{ll}
\hline KARGER & (1) 1999 S. Karger AG, Basel \\
Fax +4161306 1234 & \\
$\begin{array}{l}\text { E-Mail karger@karger.ch } \\
\text { www.karger.com }\end{array}$ & Accessible online at: \\
http://BioMedNet.com/karger
\end{tabular}

score, Shino grading system and clinical examination for anterior drawer, Lachman and pivot shift signs. The mean Lysholm knee score was 94.9 (range 71-100) while Shino grading for 64 knees was very good, for 68 knees good, and 21 knees fair. None of the patients had poor results. Conclusions: Depending on the type and degree of functional instability, we recommend anterior cruciate ligament reconstruction by autologous tendon graft and in all cases, extra-articular procedures are required.

\section{Introduction}

Anterior cruciate ligament (ACL) insufficiency often leads to significant disability. Many operations have been described for the instability of the injured knee. In most of these operations, autologous tendon graft or fascia have been used [1-3]. Allogenic tendon grafts have been used recently $[4,5]$.

\footnotetext{
Dr. Samir Abdul-Razik Ibrahim, FRCS, MD

Ortho Consultant and Head of Orthopedic Unit

Al-Razi Hospital, PO Box 4235

Safat (Kuwait)

Tel./Fax +965 4769743
} 
The most commonly used tendons are those of tibialis anterior, tendo calcaneus, the tendons of flexor muscles and the patellar tendon. The use of allogenic tendon grafts obviates creating a defect at the donor site. However, the graft needs special preparation, storage and tissue matching. The use of artificial ligaments like carbon fiber, LAD and LeedsKeio showed unsatisfactory results on the long-term follow-up, and added to that, they require special techniques and instruments.

The aim of our study was to present the results of this type of reconstruction with our standardized surgical approach and the aggressive rehabilitation program, which allow early mobilization, weight bearing and return to active normal life and sports activity.

\section{Material and Methods}

Between 1989 and 1993, 153 patients (sports players) had ACL reconstruction by K. Lambert autologous patellar tendon graft (bone patellar tendonbone), combined with MacIntosh extra-articular tenodesis. One hundred and fifty-three patients were reviewed, and all the patients were males with an average age of 23.7 years (range of 18-45 years). The right knee was involved in 87 patients and the left knee in 66 patients. All the patients sustained their injury during their sports activities: 125 patients by football, 9 patients by handball, 7 by basketball, 5 by volleyball, 1 patient by judo and 1 by boxing. The main complaint of the patients were multiple episodes of giving way, followed by swelling of the injured knee in 115 patients, while in 38 patients their knees gave way only during sports activities, and they could not participate in any such activities due to the instability of their knees. All the patients had a course of physiotherapy but their symptoms did not improve. The indications for ACL reconstructions were functional instability during daily active life, functional instability during sports activity for those who wanted to continue sports, and patients with positive Lachman sign that produced a sensation of instability. In addition, patients who had symptoms of locking and recurrent effusion caused by an associated torn meniscus were advised surgery. All the patients had positive Lachman sign in the anterior drawer test, while 131 patients had a positive pivot shift [6-8], and for 22 patients the pivot shift could not be performed or detected as they were aware of the pivot to their knees. Radiographic examination showed osteoarthritis of patella in 2 patients, and tibiofemoral changes in the same 2 patients and another 2 patients. All the patients were examined under general anesthesia before surgery to assess the instability of their knees, in comparison with the contralateral normal knees. Fifty-seven patients had preliminary arthroscopy to confirm the diagnosis and to treat any meniscal lesion arthroscopically.

\section{Operative Technique}

We used only one incision, an anterolateral incision extending from the upper border of the patella run downward and medially to the tibial tubercle. The middle third of the patellar tendon was chosen as the site of the graft. This was taken by making a parallel incision through the patellar tendon after elevating the bara patellar bursa and the paratenon. The incision was extended on to the patella and the tibial tubercle; bone plugs triangular in cross section were made with an oscillating saw using a fine blade. The average length of the plug was $2-2.5 \mathrm{~cm}$. Drill holes were made near the ends of the plugs for traction sutures to pass the plugs through the femoral and tibial tunnels. The intercondylar notch (notchplasty) was routinely enlarged.

\section{Anatomic Location of Drill Holes}

A guide wire was placed at the exact site of the ACL at the tibial attachment using a drill guide, and an 85$\mathrm{mm}$ reamer was then drilled over the guide wire to form the canal. A drill hole of the same size was made to the attachment of ACL to the femur. The patellar tendon graft with the sutures passer was used to bring the traction suture through the canal to which the bone plug was attached. The graft was passed through the femoral canal first, and then through the tibial canal.

\section{Graft Fixation}

A 30-mm cancellous screw was driven between the bone plug and the bony wall at the femoral canal first, and the knee was brought to full extension, and then a second screw was driven between the bone plug and the bony wall of the tibia.

\section{Extra-Articular Tenodesis (MacIntosh Tenodesis)}

The iliotibial band was identified proximally and distally to its insertion. A strip of the band $1 \mathrm{~cm}$ wide and about $15 \mathrm{~cm}$ long detached only proximally, and the lateral ligament which is identified is easily felt rather than to be seen. The free proximal end of the 
band threaded underneath the ligament from proximal to distal was then passed beneath the Kaplan's band. The detached end was turned and brought distally, and sutured to itself at the attachment of the band to the Gerdy's tubercle. The gap created in the band was sutured and the wound was closed with a suction drain.

Postoperatively the limb was put on a continuous passive motion machine, and the range of motion started from full extension to $30^{\circ}$ flexion, and this increased gradually, according to the tolerance of the patient to the pain. As the range of flexion reached $90^{\circ}$, the patient started active exercise and partial weightbearing on crutches. Stationary biking started when the range of flexion reached $100^{\circ}$. By 3 weeks, as a good muscle control was achieved, the weaning of the crutches started. Stationary biking was used with a medium seat position and it was gradually diminished in height, and the leg curl machine was used for the hamstring muscles. By 4-6 weeks, the range of motion usually was $110-120^{\circ}$ of flexion and above. By $6-12$ weeks, full extension and flexion were achieved, and jogging and treadmill were started, and the earliest plan on returning to sports was within 24 weeks. The patients returned to sports if the quadriceps strength was at least $70-80$ of the normal leg, with normal hamstring strength, full motion, no swelling and good stability.

Evaluation of the surgical results included subjective assessment by the patients through a questionnaire, objective finding on physical examination and radiographic evaluation. Functional assessment was graded as very good, good, fair, and poor, as proposed by Shino et al. [9]. The patient who returned to previous activity symptom-free was given very good, and good was given to the patient who returned to previous activity with slight pain, fair result to the patient who returned to previous activity with decreased range of motion and slight pain, and poor result to the patient who was not able to return to previous activity as he had significant functional instability. Lysholm knee scoring scale [10] was used to assess the functional results.

\section{Results}

\section{Follow-Up}

One hundred and fifty-three patients were reviewed (average 69.7 months, range 39-84 months), after they had their anterior cruciate ligament reconstructed using combined intraarticular (K. Lambert) and extra-articular reconstruction (MacIntosh). The time from injury to surgery was 3-13 months (average 5.9). The mechanism of injury was external rotation and valgus in 79 patients, excessive internal rotation to the tibia in 13 patients, posterior force to the tibia in 11 patients, and in 50 patients their mechanism of injury was not determined.

\section{Operative Findings}

At the operation, all the patients were found to have a torn anterior cruciate, and for 87 patients their ligament was torn at its middle, for 25 near the femoral attachment, and for 9 at the tibial attachment. In 32 cases, the site of the tear was difficult to locate. The menisci were found to be torn in 72 cases, the medial meniscus was torn in 49 cases, the lateral meniscus in 23 cases and both menisci in 1 patient. Fifteen patients had articular surface damage, 9 damage to the lateral femoral condyle, 3 to the medial femoral condyle, and 3 for both medial and lateral condyles.

\section{Clinical Results}

This was evaluated by subjective results, the final clinical examination and radiological examination. The subjective results of ACL reconstruction were evaluated by detailed questionnaires completed by each patient [9]: 64 knees had very good result, 68 kees had good result, and 21 knees had fair result. None of the patients had poor result. One hundred and thirty-one patients were able to return to their previous sports activity while 21 patients had to change their sports to having no contact with sports. None of the patients had symptoms of giving way, but 13 patients on activity complained of persistent pain associated with swelling in 5 cases. None of the patients returned to sports activity before 6 months from their surgery. The Lach- 
man test was negative in 80 patients, and the test was positive in 51 patients in grade 1 , and in 22 patients in grade 2 . Anterior drawer sign was negative in 71 patients, and positive grade 1 in 52 patients and grade 2 in 30 patients. None of the patients had positive pivot shift. Thirty-one patients had mild laxity on valgus stress when the knee was examined in full extension. Final examination showed that 12 patients had a loss of $5^{\circ}$ or less of extension, while 11 patients had a loss of $10^{\circ}$ or less of flexion. Fifty-three patients had clinical signs of patellar osteoarthritis. The Lysholm knee score [10] was 94.9 (range 71-100).

\section{Complications}

None of the patients had deep infection, except 1 patient who developed a hematoma on the outer side of the thigh which required incision and drainage. One patient had fracture patella which was fixed at the time of the surgery by a lag screw, and the patient had a very good result at follow-up. Twelve patients had $5^{\circ}$ or less loss of extension, while 11 patients had a $10^{\circ}$ or less loss of knee flexion.

\section{Discussion}

Some workers have reported that many patients with ACL-deficient knee still enjoy sports activities without functional instability $[11,12]$. On the other hand, others confirmed that patients with such insufficiency are likely to damage the menisci in 50-70\% and both in $38 \%$ of cases $[13,14]$. Extra-articular reconstruction alone showed that pivot shift sign returned in $38 \%$ of patients [15], and intraarticular reconstruction alone may not be sufficient as the graft will be under excessive load. This was reported by Butler et al. [16], who suggested that an extra-articular reconstruction might protect an intra-articular graft from excessive loading. This view was sup- ported by Engebretsen et al. [17], who found in a cadaver study that extra-articular reconstruction reduced the load on an intra-articular graft. Noyes and Barber [18] reported that combined intra-articular and extra-articular reconstruction was more successful than intra-articular graft alone, and others have described similar findings [19, 20]. The use of Leeds-Keoi ligament, in spite of being associated with fewer complications than the carbon fiber and patellar tendon graft, had improved stability and lasted for more than 3 years $[15,21,22]$. The combination of extraarticular reconstruction with an intra-articular patellar tendon graft gave satisfactory results in $93 \%$ of knees after 6 years [19] regardless of the patient's age, severity of the symptoms, or interval between injury and operation [19]. These results are superior to those of the other groups studied [22-24] and to other reported results $[25,26]$. From a review of the literature, we feel that intra-articular reconstruction as well as extra-articular augmentation are essential since the first provides the primary restraint against excessive anterior translations of the tibia on the femur, and extra-articular procedures are not sufficient by themselves for young athletes. The extraarticular procedure is needed to correct the capsular laxity secondary to recurrent subluxation. The method described intra-articular (K. Lambert) and extra-articular (MacIntosh) reconstruction to provide functional stability to patients with symptoms of anterior cruciate insufficiency, and it should be reinforced by extra-articular procedures. This procedure is limited by the amount of tissue available for reconstruction short of creating a defect at the donor site. This procedure does not introduce foreign material to the body in contrast to an allogenic tendon graft and a synthetic graft, which are expensive. It also does not require special preparation, storage or tissue matching as in allogenic tendon graft. We feel that 
young athletes with tear ACL, who have symptoms of giving way during daily activity, and whose knees give way during sports activities but who have a strong desire to continue sports, should benefit from early surgery.
Magnetic resonance imaging was not available to us, which would have helped us [27] to assess the knees preoperatively with regard to the grade and severity of the injury also associated with meniscus damage.

\section{References}

1 Clancy WG, Nelson DA, Reider B: Anterior cruciate ligament-reconstruction using one-third of patellar ligament, augmented by extra-articular tendon transfers. J Bone Joint Surg Am 1982;64A:352-359.

2 Eriksson E: Reconstruction of the anterior cruciate ligament. Orthop Clin North Am 1976;7:167-179.

3 Jones KG: Reconstruction of the anterior cruciate ligament: A technique using the central one-third of the patellar ligament. J Bone Joint Surg Am 1963;45A:925-932.

4 Shino K, Inoue M, Horibe S, et al: Reconstruction of the anterior cruciate ligament using allogenic tendon: Long-term follow-up. Am J Sports Med 1990;18:457-465.

5 Shapiro MS, Freedman EL: Allograft reconstruction of the anterior and posterior cruciate ligaments after traumatic knee dislocation. Am J Sports Med 1995;23:580-587.

6 Levy IM, Torsilli PA, Warren RF: The effect of medial meniscectomy on anterior posterior motion of the knee. J Bone Joint Surg Am 1982; 64A:883-888.

7 Kennedy JC, Stewart R, Walker DM: Anterolateral rotatory instability of the knee joint: An early analysis of the Ellison procedure. J Bone Joint Surg Am 1978;60A:10311039.

8 McDaniel WJ Jr, Damerson TB Jr: Untreated ruptures of the anterior cruciate ligament. A follow-up study. J Bone Joint Surg Am 1980; 62A:696-705.

9 Shino K, Kimura T, Hires H, Inoue $\mathrm{M}$, Ono K: Reconstruction of anterior cruciate ligament by allogenic tendon graft. J Bone Joint Surg Br 1986;68B:739-745.

10 Tegner Y, Lysholm J: Rating system in evaluation of the knee ligament injuries. Clin Orthop 1985;198:4349.

Anterior Cruciate Ligamen

Reconstruction
11 Ciccotti MG, Lombardo SJ, et al: Non-operative treatment of ruptures of the anterior cruciate ligament in middle-aged patients: Results after long-term follow-up. J Bone Joint Surg Am 1994;76A: 1315-1321.

12 Balkforts B: The course of knee-ligament injuries. Acta Orthop Scand 1982;53(suppl 198):7-99.

13 Feagin JA Jr: The syndrome of the torn anterior cruciate ligament. Orthop Clin North Am 1979;10:8190.

14 Fette JE, Marshall JL: The natural history and diagnosis of anterior cruciate insufficiency. Clin Orthop 1980;147:29-38.

15 Cross MJ, Wooffon JR, Booker DJ, Sorrenti SJ: Acute repair of injury to anterior cruciate ligament: A longterm follow-up. Am J Sports Med 1993;21:128-131.

16 Butler DL, Noyes FR, Grood ES, Miller EH, Malek M: Mechanical properties of transplants for the anterior cruciate ligament. Trans Orthop Res Soc 1979;4:81.

17 Engebretsen L, Benum P, Anda S: Extra-articular transposition of the patellar tendon for antero-lateral instability of the knee. Acta Orthop Scand 1995;66:321-324.

18 Noyes FR, Barber SD: The effect of an extra-articular procedure on allograft reconstruction for chronic ruptures of the anterior cruciate ligament. J Bone Joint Surg Am 1991; 73A:882-892.

19 Rackemann S, Robinson A, Dandy DJ: Reconstruction of the anterior cruciate ligament with an intra-articular patellar tendon graft and extraarticular tenodesis: Results after six years. J Bone Joint Surg Br 1991; 73B:368-373.

20 Kornblatt I, Warren RF, Wickiewicz TL: Long-term follow-up of anterior cruciate ligament reconstruc- tion using the quadriceps tendon substitution for chronic anterior cruciate ligament insufficiency. Am J Sports Med 1988;16:444-448.

21 O'Brien SJ, Warren RF, Pavlov H, Panariello R, Wickiewicz TL: Reconstruction of chronically insufficient anterior cruciate ligament with the central third of the patellar ligament. J Bone Joint Surg Am 1991; 73A:278-286.

22 Bray RC, Flanagan JP, Dandy DJ: Reconstruction for chronic anterior cruciate instability: A comparison of two methods after six years. J Bone Joint Surg Br 1988;70B:100-105.

23 Dandy DJ, Gray AJR: Anterior cruciate reconstruction with the LeedsKeio prosthesis plus extra-articular tenodesis. J Bone Joint Surg $\mathrm{Br}$ 1994;76B:193-197.

24 Howe JG, Warren RF, Pavlov $\mathrm{H}$, Panariello R, Wickiewicz TL: Reconstruction of the chronically insufficient anterior cruciate ligament with central third of the patellar ligament. J Bone Joint Surg Am 1991; 73A:278-286.

25 Aglietti P, Buzzi RD, Andria S, Zaccherotti G: Long-term study of anterior cruciate ligament reconstruction for chronic instability using the central one-third patellar tendon and a lateral extra-articular tenodesis. Am J Sports Med 1992;20:3845.

26 Johnson RL, Eriksson E, Haggmark T, Pope MH: Five to ten-year follow-up evaluation after reconstruction of the anterior cruciate ligament. Clin Orthop 1984;183:122139.

27 Mandelbaum BR, Finerman GAM, Reicher MA, et al: Magnetic resonance imaging as a tool for evaluation of traumatic knee injuries: Anatomical and pathoanatomical correlation. Am J Sports Med 1986;14: 361-370. 